\title{
Adenoviral-bone morphogenetic protein-7 and/or doxazosin therapies promote the reversion of fibrosis/cirrhosis in a cirrhotic hamster model
}

\author{
DANIEL CERVANTES-GARCIA ${ }^{1,2}$, ADRIANA GUADALUPE CUELLAR-JUAREZ ${ }^{3}$, \\ GISSELA BORREGO-SOTO ${ }^{4}$, AUGUSTO ROJAS-MARTINEZ ${ }^{4}$, LISETH RUBI ALDABA-MURUATO ${ }^{5}$, \\ EVA SALINAS $^{1}$, JAVIER VENTURA-JUAREZ ${ }^{5}$ and MARTIN HUMBERTO MUÑOZ-ORTEGA ${ }^{3}$
}

\footnotetext{
${ }^{1}$ Department of Microbiology, Basic Sciences Center, Autonomous University of Aguascalientes, 20131 Aguascalientes;

${ }^{2}$ National Council of Science and Technology, CONACYT, 03940 Mexico City; ${ }^{3}$ Department of Chemistry,

Basic Sciences Center, Autonomous University of Aguascalientes, 20131 Aguascalientes; ${ }^{4}$ Tecnologico de Monterrey, School of Medicine and Health Sciences, Monterrey, 64710 Nuevo Leon; ${ }^{5}$ Department of Morphology,

Basic Sciences Center, Autonomous University of Aguascalientes, 20131 Aguascalientes, Mexico
}

Received February 28, 2017; Accepted September 15, 2017

DOI: $10.3892 / \mathrm{mmr} .2017 .7785$

\begin{abstract}
Liver fibrosis occurs in the presence of continuous insults, including toxic or biological agents. Novel treatments must focus on ceasing the progression of cellular damage, promoting the regeneration of the parenchyma and inhibition of the fibrotic process. The present study analyzed the effect of bone morphogenetic protein (BMP)-7 gene therapy with or without co-treatment with doxazosin in a model of liver cirrhosis in hamsters. The serum alanine aminotransferase, aspartate aminotransferase and albumin levels were analyzed spectrophotometrically. Tissue hepatic samples were analyzed by hematoxylin and eosin for parenchymal structure and Sirius red for collagen fiber content. BMP-7 and $\alpha$-smooth muscle actin (SMA)-positive cells were detected by immunohistochemistry. BMP-7 and collagen type I content in hepatic tissue were analyzed by western blotting, and tissue inhibitor of metalloproteinases (TIMP)-2 and matrix metalloproteinase (MMP)-13 expression levels were detected by reverse transcription-quantitative polymerase chain reaction. The present study detected a significant reduction of collagen type I deposits in the group treated with adenoviral-transduction with BMP-7 and doxazosin. In animals with BMP-7 and doxazosin therapy, $\alpha$-SMA-positive cells were 31.7 and $29 \%$ significantly decreased compared with animals with placebo, respectively. Adenoviral-BMP-7 transduction and/or doxazosin treatments actively induced decrement in type I collagen
\end{abstract}

Correspondence to: Dr Martin Humberto Muñoz-Ortega, Department of Chemistry, Basic Sciences Center, Autonomous University of Aguascalientes, 940 University Avenue, 20131 Aguascalientes, Mexico

E-mail:mhmunoz@correo.uaa.mx

Key words: fibrosis, cirrhosis, collagen type I, bone morphogenetic protein-7, doxazosin, hepatic stellate cells deposition via increased MMP-13 and reduced TIMP-2 expression. In conclusion, the adenovirus-BMP-7 gene therapy and the doxazosin therapy are potential candidates for the diminution of fibrosis in the liver, although combination of both therapies does not improve the individual anti-fibrotic effect once cirrhosis is established.

\section{Introduction}

Worldwide, liver cirrhosis is considered an important global health burden, with more than one million deaths in 2010 (1). Liver cirrhosis and fibrosis are chronic inflammatory diseases in which excessive wound healing is associated to multiple etiologies such as alcohol abuse, metabolic disorders, immune disease and viral infections $(2,3)$. They are characterized by over deposition of extracellular matrix (ECM), with reduced expression of matrix metalloproteinases (MMPs) and increased expression of tissue inhibitor of metalloproteinases (TIMPs), and the consequent loss of liver functions $(4,5)$. Fibrotic tissue increases the regenerative nodules and the distortion of the vascular function is responsible for most of the complications in this liver disease (6). The activation of hepatic stellate cells (HSCs) to the miofibroblasts phenotype plays a remarkable role during the pathogenesis of fibrosis and the establishment of liver cirrhosis (7). Growing evidence is demonstrating that inhibition of transforming growth factor (TGF)- $\beta$, an activator of HSCs, shows promising effects in the treatment of liver fibrosis (7-9). TGF- $\beta$ is considered as a crucial profibrogenic cytokine involved in the fibroblasts recruitment, differentiation of miofibroblasts, epithelial-mesenchymal transition (EMT) and deposition of ECM $(10,11)$.

Some drugs and pathways are being used as target for the blockage of fibrotic process, like angiogenesis inhibitors, antihypertensive drugs as angiotensin inhibitors, downregulation of TGF- $\beta$, and cell therapy strategies (12). Recently doxazosin, an $\alpha$-blocker of adrenergic receptors, has been proposed as a potential antifibrotic drug in an experimental model of 
cirrhosis induced with carbon tetrachloride (CCl4). After 6 weeks of treatment with doxazosin, a significant reduction in deposits of collagen type I was observed in cirrhotic livers, which was associated with a decrease in TGF- $\beta$ synthesis (13). Nevertheless, doxazosin antifibrotic effect at shorter periods of treatment has not been studied on cirrhotic animals. Doxazosin is usually used to treat patients with hypertension by avoiding the norepinephrine binding to $\alpha 1$-adrenergic receptors (14). Moreover, doxazosin relieves benign prostatic hypertrophy symptoms through the relaxing of the smooth muscles surrounding the prostate, so that it can reduce the urine retention and diminish bladder outlet obstruction (15).

In addition to reducing the complications in cirrhotic patients, new treatments must be focused on ceasing the progression of cellular damage, by promoting the regeneration of parenchyma and the inhibition of fibrotic process. Gene therapy coupled with standard drugs is a promising and viable alternative to alleviate liver chronic diseases in order to recover hepatocellular functions, improve portal pressure and arrest the progression of the liver fibrosis $(7,16)$. Bone morphogenetic proteins (BMPs) are members of related proteins that belong to the superfamily of TGF- $\beta$ with 47 identified members (17). BMPs have been described as excellent inducers of bone and cartilage, due to their capacity to induce cellular differentiation through cell signaling after receptor binding. BMPs also play pleiotropic roles in various biological processes in digestive tube, heart, brain, gonads, liver and skin (18-21). After binding to their receptors, a downstream Smad signaling is triggered with the consequent activation of target genes, mainly related to cellular proliferation and differentiation $(22,23)$. It has been reported that BMP-7 causes the inhibition of the intracellular signaling initiated by TGF- $\beta$, through the blockage of Smad 3/4, and diminishes the effects of TGF- $\beta$ (24-26). In absence of BMP-7, TGF- $\beta$ binding to its receptor initiates the phosphorylation of Smad-2 and Smad-3 proteins, which join Smad-4 to form a complex which is translocated to the nucleus and activates the collagen type I synthesis and EMT activation. Otherwise, BMP-7 downstream signaling via activation of Smad-1, Smad-5 and Smad-8 can antagonize the effect of Smad-2/-3 through the heterodimerization with Smad-4, thereby Smad-3 is accumulated outside the nucleus $(27,28)$. Several studies show that recombinant BMP-7 protein administered to animals reduces the fibrosis in kidney, lung and liver, by downregulating fibrotic markers such as collagen, $\alpha$-smooth muscle actin (SMA) and TGF- $\beta$ expression (29-32).

In this study, we analyzed the effect of BMP-7 gene therapy alone or in co-treatment with doxazosin in a model of liver cirrhosis in hamster. Our results suggest that the strategy combining BMP-7 gene therapy and doxazosin is useful for the reversion of liver cirrhosis.

\section{Materials and methods}

Animals. Six-to eight-weeks old male golden hamsters (Mesocricetus auratus), from 100 to $150 \mathrm{~g}$ weight, were maintained in the local Animal Core Facility with $12 \mathrm{~h}$ light/dark cycles and fed with Nutricubos (Ralston Purina Company, St. Louis, MO, USA) and water ad libitum. All animal experiments were approved by the Animal Welfare and Research Ethics Committee of the Autonomous
University of Aguascalientes (Aguascalientes, Mexico), and were conducted in accordance with institutional guidelines for caring for experimental animals and the national regulatory norm NOM-062-Z00-1999. Thirty animals were randomly distributed as follows: i) intact hamsters $(n=5)$ (Intact group) and ii) experimental hamsters induced with cirrhosis by two intraperitoneal injections of $50 \mathrm{mg} / \mathrm{kg}$ of CCl4 per week for 18 weeks $(n=25)$. Intact animals and five experimental hamsters (Cirrhotic group) were sacrificed at week 18 to demonstrate the fibrosis/cirrhosis grade, collecting blood and liver samples. Photographs in two positions, liver anterior region and portal vein were documented with an Olympus xD Master 2 (SP-55OUZ; Olympus Corporation, Tokyo, Japan).

Adenoviral-BMP-7 transduction and doxazosin therapies. Experimental hamsters were divided in four groups with 5 animals per group: i) Placebo, treated orally with water and via portal with a single injection of adenoviral storage buffer as vehicle (10 mM Tris, $\mathrm{Ph} 8.0,100 \mathrm{mM} \mathrm{NaCl}$, and 50\% glycerol); ii) Doxa, orally treated with doxazosin $1 \mathrm{mg} / \mathrm{kg} / \mathrm{day}$; iii) BMP-7: treated via portal with a single injection of $1 \times 10^{9}$ PFU adenoviral vector Ad-BMP-7, as previously reported (33), and iv) BMP-7/Doxa, treated with the same doses and times that BMP-7 and Doxa groups. All treatments were administered for 2 weeks, once cirrhosis was established, and later animals were euthanized for specimen collection of liver and blood. Liver photographs were taken and tissue samples were fixed in neutral formalin. Serum samples were frozen at $-80^{\circ} \mathrm{C}$ until used. The experimental protocol and treatment schedules for each group are illustrated in Fig. 1.

Protein extraction and Western blot analysis. To analyze the expression of BMP-7 and collagen type I in the liver parenchyma, $100 \mathrm{mg}$ of tissue was homogenized in $1 \mathrm{ml}$ of lysis buffer (Tris-HCl $50 \mathrm{mM}$ pH 6.8, N-ethylmaleimide $5 \mathrm{mM}$, iodoacetamide $3 \mathrm{mM}$, phenylmethanesulfonyl fluoride $1 \mathrm{mM}$ and tosyl-L-lysine chloromethyl ketone $3 \mathrm{mM}$ ) for total protein extraction. The lysate was centrifuged at 40,000 x g for $1 \mathrm{~h}$ at $4^{\circ} \mathrm{C}$. The supernatant was recovered and proteins quantified with the Bradford method (34).

For western blot, $50 \mu \mathrm{g}$ of each protein extract was separated in a $12 \%$ SDS-PAGE gel, and proteins were transferred to a PVDF membrane (Bio-Rad, Hercules, CA, USA). Blockage was achieved for $1 \mathrm{~h}$ at room temperature with TBST (Tris-buffered saline/0.05\% Tween-20) and 5\% skimmed milk. For immunodetection, membrane was incubated for $1 \mathrm{~h}$ at room temperature with: $0.2 \mu \mathrm{g} / \mathrm{ml}$ goat polyclonal anti BMP-7 (Santacruz Biotechnology, Dallas, Tx, USA), $1 \mu \mathrm{g} / \mathrm{ml}$ mouse monoclonal anti collagen type I (Sigma-Aldrich, St. Louis, MO, USA) or $1 \mu \mathrm{g} / \mathrm{ml}$ rabbit polyclonal anti $\beta$-actin (Abcam, Cambridge, UK). Then, blots were incubated with the alkaline phosphatase (AP)-conjugated antibodies: $1 \mu \mathrm{g} / \mathrm{ml}$ rabbit anti-goat (Merk-Millipore, Darmstadt, GE), $0.25 \mu \mathrm{g} / \mathrm{ml}$ goat anti-mouse (Sigma-Aldrich), or $0.5 \mu \mathrm{g} / \mathrm{ml}$ goat anti-rabbit (Abcam), respectively. After three washes with TBS, blotting was developed with Sigma Fast BCIP ${ }^{\circledR} /$ NTB (Sigma-Aldrich). Analysis of collagen type I, BMP-7 and $\beta$-actin expression was performed with the ImageJ software (National Institutes of Health, Bethesda, MD, USA). Mean of Intensity of collagen type I and BMP-7 bands were normalized respect to that of 
Table I. Oligonucleotides sequences.

\begin{tabular}{lllc}
\hline Gene & \multicolumn{1}{c}{ Oligonucleotides } & Accession number & Amplicon size \\
\hline MMP-13 & & XM_005077319.1 & $246 \mathrm{pb}$ \\
$\mathrm{F}$ & TGTCCTGGCCACTCTCTTCT & & \\
$\mathrm{R}$ & GGGTCATCAAGTTTGCCAGT & AF260255.1 & $196 \mathrm{pb}$ \\
TIMP-2 & & & $115 \mathrm{pb}$ \\
$\mathrm{F}$ & TCAAAGGCCCTGACAAAGAC & NM_001281595.1 & \\
$\mathrm{R}$ & AGGCTCTTCTTCTGGGTGGT & & \\
$\mathrm{F}$-actin & GCCCAGAGCAAGAGAGGTAT & & \\
$\mathrm{R}$ & CACGCAGCTCGTTGTAGAAG & & \\
\hline
\end{tabular}

MMP-13, matrix metalloproteinase-13; TIMP-2, tissue inhibitor of metalloproteinases; F, forward; R, reverse.

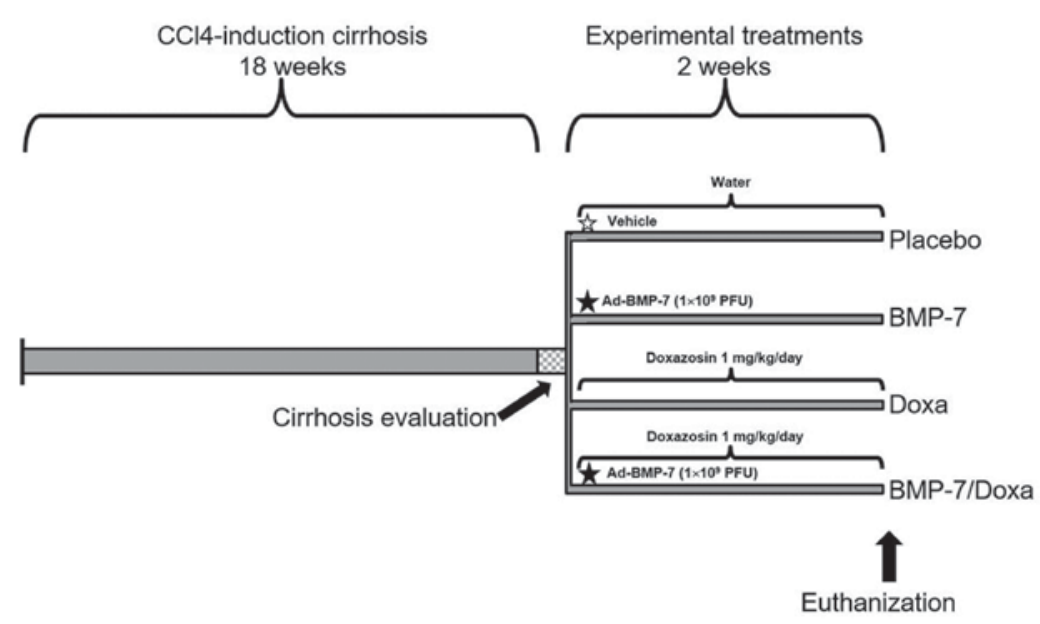

Figure 1. Time schedule of the CCl4-induced cirrhosis hamster model and experimental treatments. CC14, carbon tetrachloride BMP-7; bone morphogenetic protein-7; Doxa, Doxazosin.

$\beta$-actin, as internal control and ratios BMP-7/collagen type I were calculated.

Liver function tests. The serum markers of liver damage: alanine aminotransferase (ALT), aspartate aminotransferase (AST) and albumin were quantified in an Biosystems analyzer (bts-350; Biosystems, Quezon City, Philippines).

Histochemical and Immunohistochemical analysis. Tissues were paraffin-embedded and $5 \mu \mathrm{m}$ sections were obtained and stained with hematoxylin and eosin (H\&E) and Sirius red techniques to evaluate parenchymal architecture and deposits of collagen type I or III as result of ECM rearrangement. Percent of fibrotic area was determined with the measure of fibrotic area in relation to the total area of the tissue. Morphometric analysis was performed with Image Pro Plus Software 4.5.1 (Media Cybernetics, Bethesda, MD, USA). Immunohistochemistry was performed to analyze BMP-7- and $\alpha$-SMA-positive cells in liver tissues. Briefly, liver tissue slides were incubated with $2 \mu \mathrm{g} / \mathrm{ml}$ goat polyclonal anti-BMP-7 (Santa Cruz Biotechnology) or $10 \mu \mathrm{g} / \mathrm{ml}$ rabbit polyclonal anti- $\alpha$-SMA (Abcam) for $12 \mathrm{~h}$ at $4^{\circ} \mathrm{C}$. As a secondary antibody,
$4 \mu \mathrm{g} / \mathrm{ml}$ rabbit anti-goat (Merk-Millipore) conjugated with AP or EnVision+/Dual Link System-HRP anti Rabbit/Mouse (Dako, Carpinteria, CA, USA), was respectively used. The AP activity for BMP-7 detection was developed with the Sigma Fast BCIP ${ }^{\circledR} /$ NTB (Sigma-Aldrich), and the HRP activity for $\alpha$-SMA detection with Sigma Fast Diaminobenzidine (Sigma-Aldrich). Number of $\alpha$-SMA-positive cells were counted in all slide and reported as cells $/ \mathrm{mm}^{2}$. Data was documented in a Zeiss Axioscope 40/40FL microscope (Zeiss, Oberkochen, Germany) and analyzed with the Image Pro Plus Software 4.5.1 (Media Cybernetics).

Isolation of total RNA and reverse transcription-quantitative polymerase chain reaction $(R T-q P C R)$. Total RNA was isolated from $100 \mu \mathrm{g}$ of liver of the control and experimental animals with the SV Total RNA Isolation System (Promega, Madison, WI, USA) following the manufacturer's protocol. Total RNA was stored at $-80^{\circ} \mathrm{C}$ until use. Reverse transcription for cDNA synthesis was performed with $1 \mu \mathrm{g}$ of total RNA using the GoScript Reverse Transcription System (Promega) and real time qPCR with the buffer GreenMaster with UNG-clear (Jena Bioscience, Jena, Germany) in a 
A
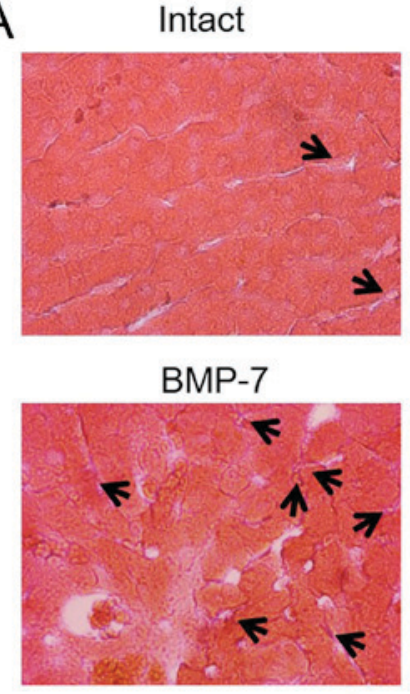

Cirrhotic

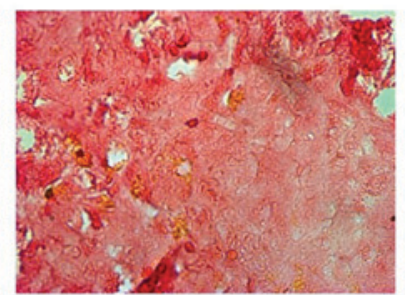

Doxa

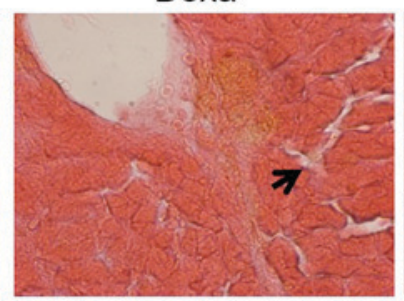

Placebo

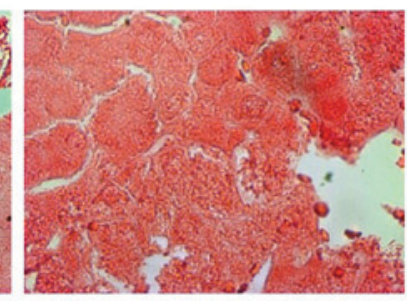

BMP-7/Doxa

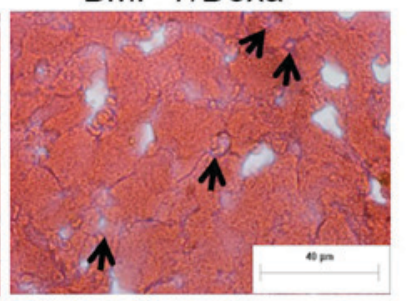

B

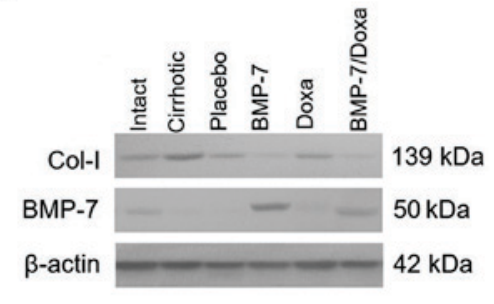

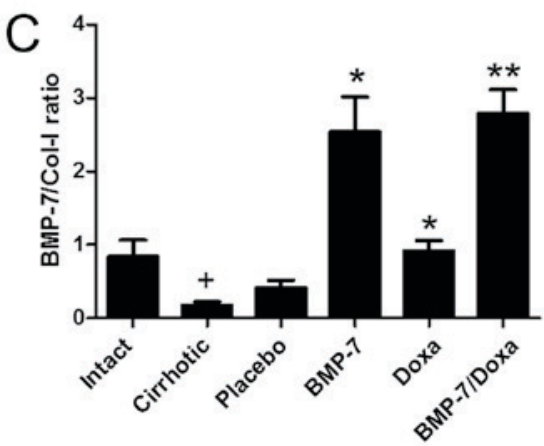

Figure 2. Evaluation of BMP-7 and collagen type I expression in cirrhotic hamsters. (A) Immunohistochemistry for identification of BMP-7-positive secreting hepatocytes (black arrows) after two weeks of adenoviral administration. (B) Western blot for collagen type I (Col-I) and BMP-7 expression in liver tissue. (C) Densitometry determination is represented as BMP-7/collagen type I ratios. Data is presented as mean \pm SEM. ${ }^{+} \mathrm{P}<0.001$ vs. Intact; ${ }^{*} \mathrm{P}<0.05$ and ${ }^{* *} \mathrm{P}<0.005$ vs. Placebo. BMP-7, bone morphogenetic protein; Doxa, Doxazosin, Col-I, collagen type I; SEM, standard error of the mean.

StepOne Real-Time PCR Machine (Thermo Fisher Scientific, Inc., Waltham, MA, USA). Oligonucleotides were designed to target on MMP-13, TIMP-2, and actin as a reference control (Table I). The RT-PCR program used for all targets was: $50^{\circ} \mathrm{C}$ for $2 \mathrm{~min}, 95^{\circ} \mathrm{C}$ for $45 \mathrm{sec}, 40$ cycles of $95^{\circ} \mathrm{C}$ for $45 \mathrm{sec}$ and $60^{\circ} \mathrm{C}$ for $45 \mathrm{sec}$, and extension at $72^{\circ} \mathrm{C}$ for $12 \mathrm{sec}$. Relative quantification of target mRNA expression was calculated by the $\Delta \Delta \mathrm{Ct}$ method using $\beta$-actin for normalization (35).

Statistical analysis. GraphPad Prism V5 software (GraphPad Software, Inc., La Jolla, CA, USA) was employed for statistical analysis. Data are expressed as the mean \pm standard error of the mean (SEM) of five animals. Significant differences between mean values were evaluated by using the two tailed Student's $\mathrm{t}$ test. Statistical significance was considered at $\mathrm{P}<0.05$.

\section{Results}

Expression of BMP-7 and its relationship with collagen type I levels in hepatic parenchyma of transduced $\mathrm{CCl} 4$-induced cirrhosis hamsters. The administration of $1 \times 10^{9} \mathrm{PFU}$ of the vector via porta was efficiently tolerated by animals. To confirm protein expression of BMP-7 in the hepatic parenchyma of transduced animals, immunohistochemistry and Western blot was developed in liver tissue (Fig. 2). Immunohistochemical examination showed BMP-7 secreting hepatocytes in liver from BMP-7 and BMP-7/Doxa animals (Fig. 2A, black arrows). BMP-7 native production was also detected in Intact and Doxa groups, and remains almost undetectable in Placebo and Cirrhotic animals. Similar results were obtained by western blot analysis, as seen in Fig. 2B. Although basal expression of BMP-7 was present in Intact, Cirrhotic, Placebo and Doxa groups, the expression of the protein was much higher in the groups BMP-7 and BMP-7/Doxa after 2 weeks of adenoviral delivery. Also, BMP-7 expression was correlated with collagen type I production, since an increase in BMP-7 levels in BMP-7 and BMP-7/Doxa groups was associated with a decrease in the levels of collagen type I (Fig. 2B). The densitometric analysis revealed that cirrhotic animals decreased BMP-7/Col-I ratio, but vector administration significantly increased 6.1- and 6.7-fold BMP-7/Col-I ratio in BMP-7 and BMP-7/Doxa groups, respect to Placebo animals (Fig. 2C). When doxazosin was administered alone, although collagen type I expression was similar to Placebo group, there was also an increase in BMP-7/Col-I ratio in these animals that was 2-fold higher that in Placebo group. 

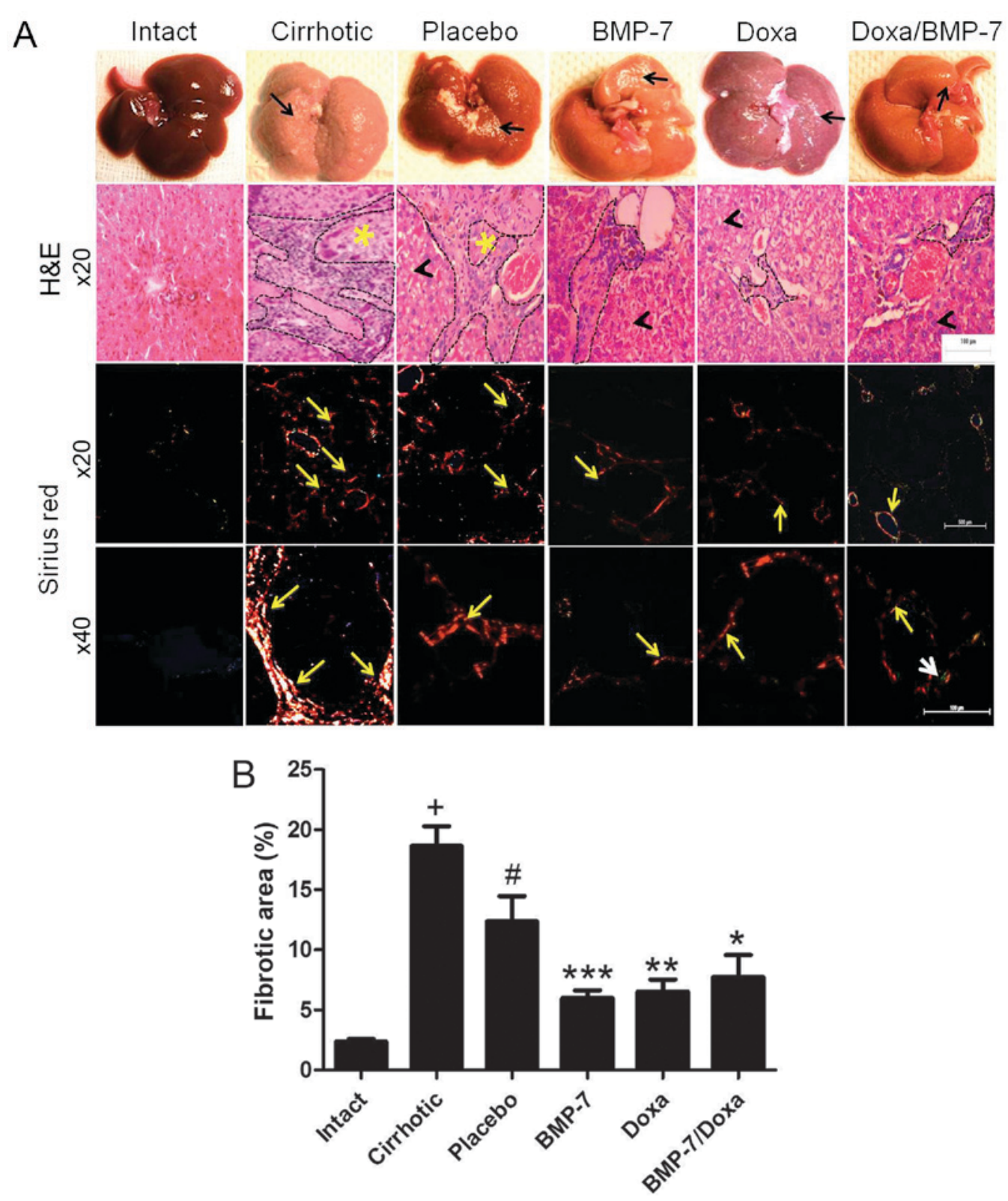

Figure 3. Liver macroscopic observation and histological analysis for the acinus architecture remodeling and collagen deposition in experimental groups. (A) Representative pictures of livers from experimental groups and the corresponding microphotographs of slides stained with $\mathrm{H} \& \mathrm{E}$ (magnification, $\mathrm{x} 20$ ) or Sirius red (magnification, x20 and x40) techniques. Black arrows show granulated aspect of the livers; black arrowheads indicate histological aspect of hepatocytes; black dashed lines demarcate inflammatory infiltrates; yellow asterisks mark regenerative nodules; yellow arrows point to collagen type I fiber; and white arrow to collagen type III fibers. (B) Percentage of fibrotic area was determined by measuring the amount of fibrotic area in respect to whole area. Data is presented as mean \pm SEM. ${ }^{+} \mathrm{P}<0.001$ vs. Intact; ${ }^{*} \mathrm{P}<0.01$ vs. Cirrhotic; ${ }^{*} \mathrm{P}<0.05,{ }^{* * *} \mathrm{P}<0.005$ and ${ }^{* * *} \mathrm{P}<0.001$ vs. Placebo. BMP-7, bone morphogenetic protein; Doxa, Doxazosin; SEM, standard error of the mean.

Regression of cirrhosis with $\alpha$-adrenergic receptor antagonist and therapy with BMP-7. The histological changes and accumulation of collagen type I were evaluated by studying liver architecture and collagen type I deposition by H\&E and Sirius red staining under light microscopy and polarized-light microscopy (Fig. 3A). The macroscopic observation of Intact group livers evidenced normal aspect, shape and dark-browned color. The H\&E staining showed the liver parenchyma well organized in acinus with a central vein. Moreover, Sirius red staining did not reveal collagen type I accumulation at magnification, $\mathrm{x} 20$ and $\mathrm{x} 40$. In the Cirrhotic group, livers had granulated surface (black arrow); the H\&E images showed a wide area of inflammatory infiltrate and possible fibrosis (black dashed line) that delimited the regenerative nodules (yellow asterisk). Sirius red staining evidenced several circles of collagen type I surrounding regenerative nodules (x20, yellow arrow), in which collagen type I accumulated in the periphery ( $\mathrm{x} 40$, yellow arrow). The livers in the Placebo group were similar to the Cirrhotic group, with granulated surface (black arrow). We observed an inflammatory infiltrate (black dashed outline) in the tissue architecture, and hepatocytes appeared edematous (black arrowhead). After observation at magnification, x20 and x40 with Sirius red staining, liver slides had lesser aggregation of collagen type I fibers (yellow arrows) when compared to the Cirrhotic group. Livers from BMP-7 group had reduced granulation on their surface (black arrow), 

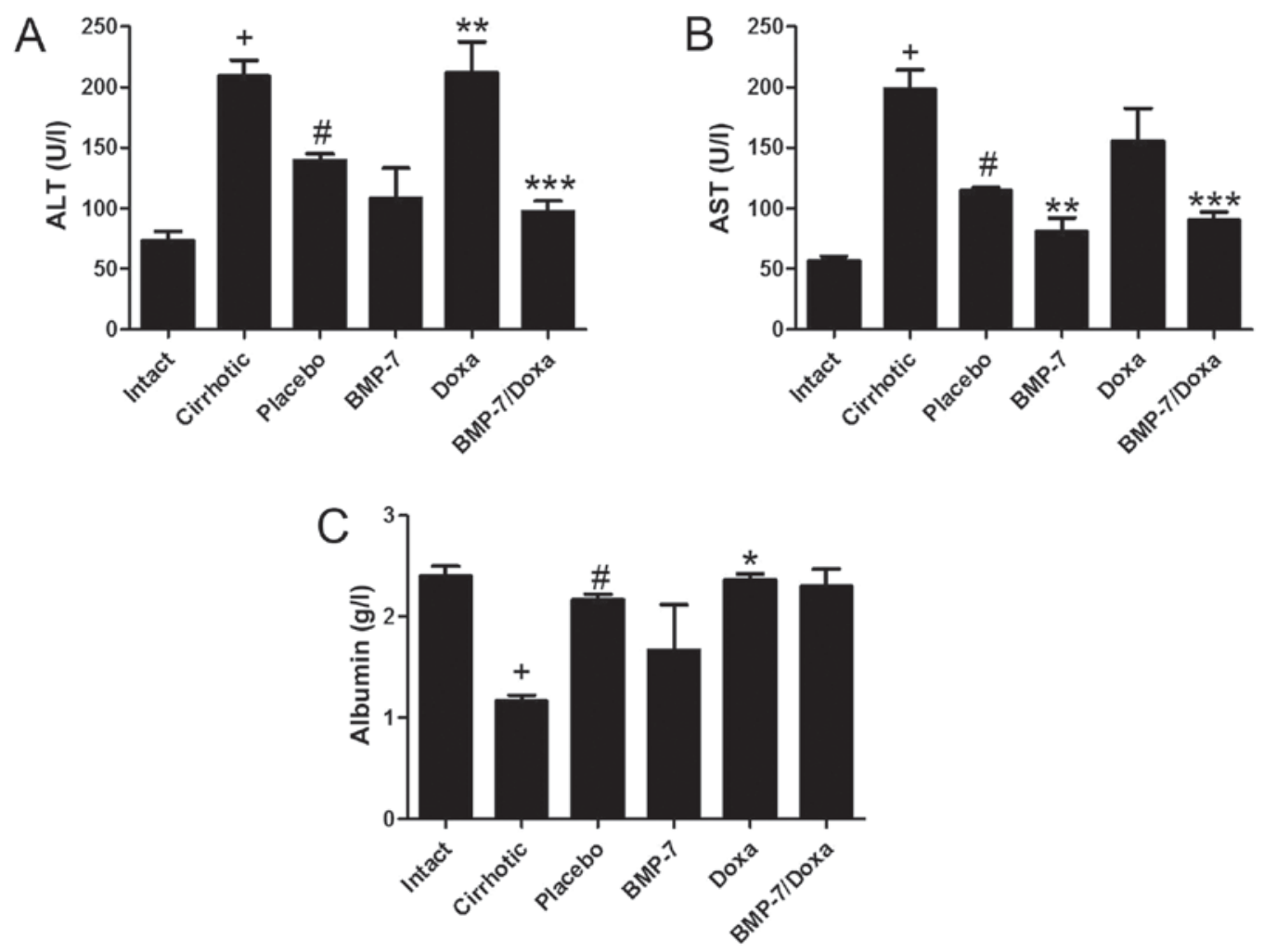

Figure 4. Liver function assessment by quantification of serum levels of (A) ALT, (B) AST activities and (C) albumin concentration. Data is presented as mean \pm SEM. ${ }^{+} \mathrm{P}<0.001$ vs. Intact; ${ }^{*} \mathrm{P}<0.005$ vs. Cirrhotic; ${ }^{*} \mathrm{P}<0.05,{ }^{* * *} \mathrm{P}<0.01$ and ${ }^{* * * *} \mathrm{P}<0.005$ vs. Placebo. ALT, alanine aminotransferase; BMP-7, bone morphogenetic protein; AST, aspartate aminotransferase; Doxa, Doxazosin; SEM, standard error of the mean.

liver parenchyma showed less inflammatory infiltrate (black dashed line) surrounding hepatocytes with notable reduction of edema (black arrowhead), and reduced fibers of collagen type I (yellow arrows). Doxazosin-treated cirrhotic hamsters had little granulation on the liver surface (black arrow); like in the BMP-7 group, scarce inflammatory infiltrate (black dashed line) and some edematous hepatocytes were observed (black arrowhead), and collagen type I fibers (yellow arrows) were markedly reduced when compared to Placebo group. In the group that received the double treatment (BMP-7/Doxa), the surfaces of the livers were barely granulated (black arrow), liver parenchyma showed few inflammatory infiltrate (black dashed line) surrounding morphologically healthy hepatocytes (black arrowhead). Outstandingly, the observation of the Sirius red staining showed scarce deposits of collagen type I (yellow arrows) and merging fibers of collagen type III (white arrow).

The measurement of the fibrotic area clearly demonstrated a significant 7.8-fold increment of collagen type I deposits in liver of cirrhotic animals. Placebo group showed a spontaneous $33.6 \%$ decrease of these collagen deposits. However, the treatment with adenoviral BMP-7-transduction induced a reduction of $51.6 \%$ of collagen type I deposits, and Doxa group had 47.1\% reduced collagen type I accumulation, when compared to Placebo group. The percent of the fibrotic area was reduced $37.4 \%$ in cirrhotic hamster treated with doxazosin and BMP-7 in comparison to the Placebo group (Fig. 3B). BMP-7 did not improve the antifibrogenic effect of doxazosin, as there were not differences between Doxa and BMP-7/Doxa groups. These data demonstrated that both adenoviral-BMP-7 gene and doxazosin treatment are potential candidates for decreasing liver fibrosis, although combination of both therapies do not improve their individual antifibrotic effect once cirrhosis is stablished.

Recovery of liver function in BMP-7 transduced and/or Doxa treated animals. The plasma levels of liver enzymes ALT and AST, and albumin were measured to determine the liver function in experimental groups (Fig. 4). Liver function tests supported the histological findings in $50 \mathrm{mg} / \mathrm{kg} \mathrm{CCl} 4$-induced hamsters treated with BMP-7 and BMP-7/Doxa. As expected, the cirrhotic group had significantly increased levels of ALT and AST, and diminished concentration of albumin when compared to Intact group. Animals from Placebo group showed a spontaneous recovery of these biochemical markers of hepatic damage, as they decrease in 33.2 and $42.3 \%$ the levels of ALT and AST and increase in $86.2 \%$ albumin concentration in blood. In the BMP-7 group, adenoviral-BMP-7 transduction significantly lowered the levels of AST (29.6\%) as compared to the Placebo group, although ALT and albumin remained without significant changes. However, after two weeks of doxazosin treatment (Doxa group), ALT levels and albumin were 34.1 and 6\% higher than in the Placebo group, respectively, which presumably indicates hepatotoxic activity of doxazosin. Moreover, adenoviral-BMP-7 transduction and doxazosin treatment induced significant diminution of ALT and AST levels, while concentration of albumin was unchanged, as compared to Placebo group. These results suggest that BMP-7 over-expression combined with doxazosin may reduce the biochemical abnormalities after hepatic damage induced 
A

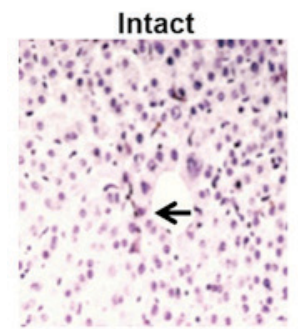

Placebo

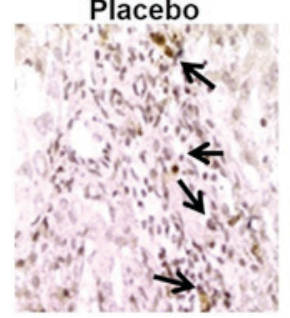

Doxa
Cirrhotic

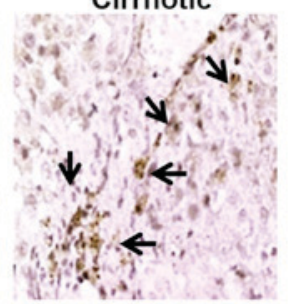

BMP-7

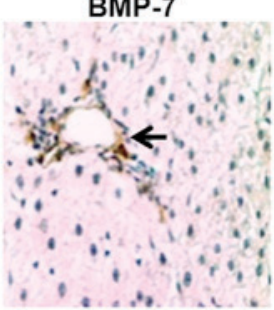

Doxa/BMP-7

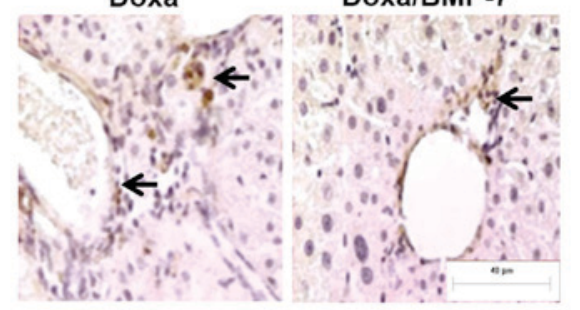

B

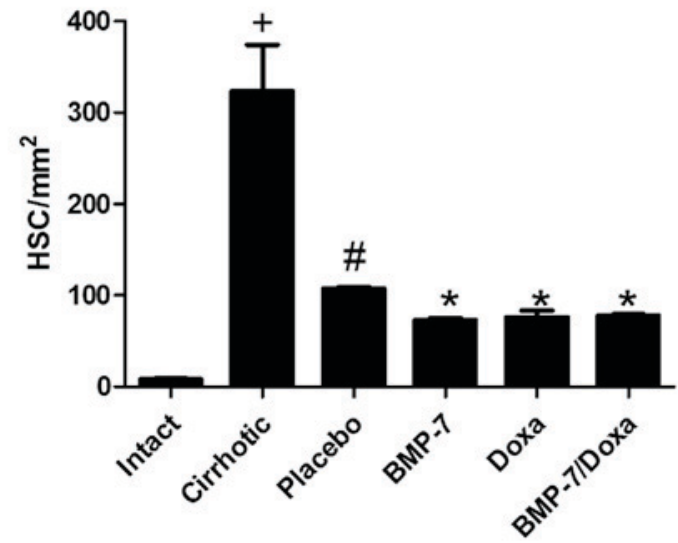

Figure 5. Immunohistochemical quantification of $\alpha$-SMA-positive cells in cirrhotic livers after adenoviral-BMP-7 transduction and doxazosin treatments. (A) Representative microphotographs observed at 20x, black arrows indicate HSCs. (B) Morphometric analysis of $\alpha$-SMA-positive cells per unit of area. Data is presented as mean \pm SEM. ${ }^{+} \mathrm{P}<0.001$ vs. Intact; ${ }^{\prime} \mathrm{P}<0.005$ vs. Cirrhotic; $\mathrm{P}<0.005$ vs. Placebo. HSC, hepatic stellate cells; BMP-7, bone morphogenetic protein; Doxa, Doxazosin; SEM, standard error of the mean.
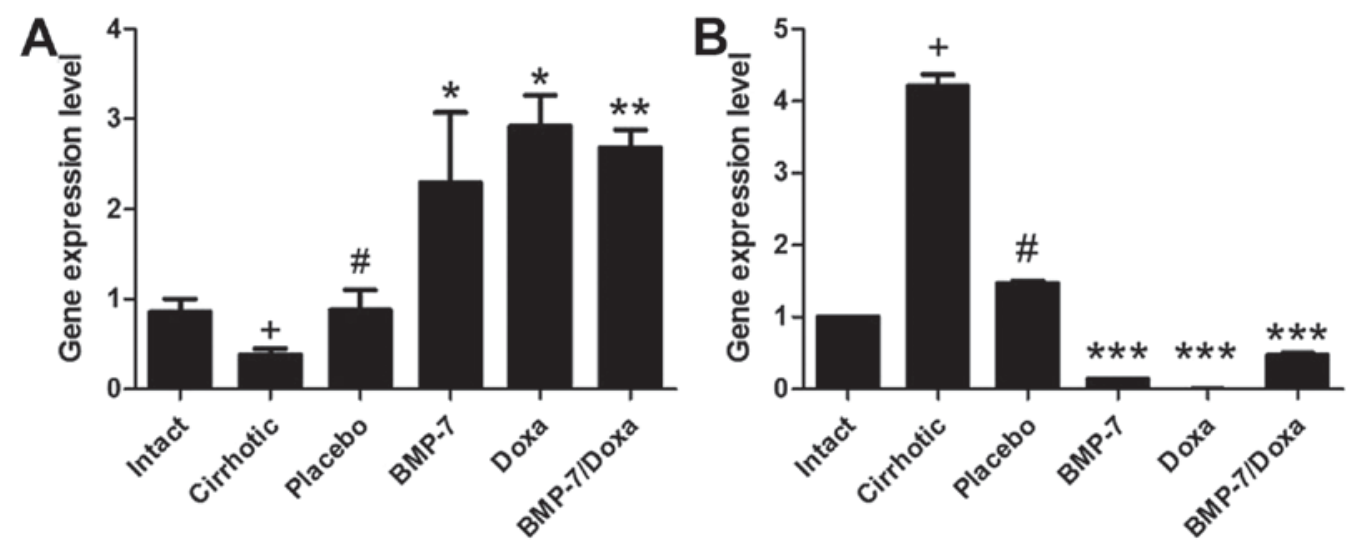

Figure 6. Gene expression levels of (A) MMP-13 and (B) TIMP-2. Data is presented as mean \pm SEM. ${ }^{+} \mathrm{P}<0.005$ vs. Intact; ${ }^{\#} \mathrm{P}<0.05$ vs. Cirrhotic; ${ }^{*} \mathrm{P}<0.05$, ${ }^{* *} \mathrm{P}<0.01$ and ${ }^{* * *} \mathrm{P}<0.001$ vs. Placebo. MMP, matrix metalloproteinase; TIMP, tissue inhibitor of metalloproteinases; BMP-7, bone morphogenetic protein; Doxa, Doxazosin; SEM, standard error of the mean.

with $\mathrm{CCl} 4$, even when two weeks of doxazosin treatment appear to induce toxic effects in the cirrhotic liver.

Analyses of hepatic fibrosis by immunohistochemistry for HSCs. To correlate changes in number of activated HSCs to the fibrosis reduction, we analyzed the number of $\alpha$-SMA-positive cells in hepatic tissue from $50 \mathrm{mg} / \mathrm{kg}$ CCl4-induced hamsters treated with adenoviral-BMP-7 transduction and/or doxazosin (Fig. 5A). As expected, the amount of activated HSCs in liver of cirrhotic animals was 40.4-fold higher than in Intact hamsters. When cirrhotic animals were placebo administered there was a spontaneous decrease of $66.9 \%$ in the number of liver activated HSCs. In the BMP-7 and Doxa groups, $\alpha$-SMA-positive cells were 31.7 and $29 \%$ significantly lower than in the Placebo. Combination of BMP-7-adenoviral transduction and Doxa did not improve reduction of $\alpha$-SMA-positive cells in liver parenchyma once cirrhosis was stablished (Fig. 5B). Taken together, these data indicated that Doxa and BMP-7 exert the antifibrotic effect, at least in part, by reduction of HSCs; although the combination of both treatments does not increase the reduction of this activated cell population. 
Changes in MMP-13 and TIMP-2 expression are associated to antifibrotic effect of experimental treatments. We further examined MMP-13 (Fig. 6A) and its inhibitor TIMP-2 (Fig. 6B) mRNA expression, as both molecules are involved in ECM remodeling. As it is known that occurs in cirrhotic damage, MMP-13 expression was significant decreased in liver of Cirrhotic animals while that of TIMP-2 was increased. Placebo administration increased 2.3-fold MMP-13 expression and diminished in a $65.2 \%$ TIMP-2 mRNA levels. Consistent with the histological data, the experimental treatments were associated with upregulated MMP-13 mRNA expression, as well as downregulated TIMP-2 mRNA. In the BMP-7 group, MMP-13 and TIMP-2 were inversely regulated with increment of 2.6-fold and reduction of 11.2-fold, respectively, when compared to Placebo group. Also, Doxa treatment promoted a 3.3-fold increased expression of MMP-13 and almost undetectable expression of TIMP-2. Nevertheless, BMP-7/Doxa group had 3.0-fold increased expression of MMP-13 mRNA and TIMP-2 mRNA was 3.1-fold lowered than Placebo group. These data suggest that BMP-7-adenoviral transduction and/or doxazosin treatments induce decrement in the collagen type I deposition by increasing MMP-13 expression and reducing TIMP-2 expression. These finding are consistent with collagen type I accumulation in the cirrhotic animals. However, the combined BMP-7/Doxa therapy does not exceed the benefits observed in the separates treatments.

\section{Discussion}

Cirrhosis represents the major pathological outcome of continuous insult to the liver and it also precludes the development of hepatocellular carcinoma in some patients. Currently, drugs targeting fibrosis in clinical practice are attracting the interest of researchers, who have generated innovative therapeutic strategies addressed to target fibrogenic cytokines, such as TGF- $\beta$, with blocking peptides (36), or through the inhibition of HSCs activation (37). Thus, in the present study, we evaluated whether the drug therapy with the $\alpha$-adrenergic blocker doxazosin or gene therapy through adenoviral transduction of BMP-7, could have antifibrotic effects as individual or combined treatments in a hamster model of CCl4-induced cirrhosis.

Spontaneous reversion of the liver cirrhosis after cessation of the CCl4-induction has been well documented (38-40). We observed spontaneous improvement in the fibrotic process and liver function in animals from Placebo group. Chávez et al demonstrated spontaneous resolution of liver fibrosis in vehicle treated CCl4-induced rats. The placebo treatment also diminished the levels of ALT in CCl4-induced cirrhosis even after 4 weeks of discontinued induction (41). Besides, other authors reported that the spontaneous reversal of cirrhosis after 6 weeks of vehicle daily administration was accompanied by diminution of $\alpha$-SMA positive cells and down-expression of TIMP-1, as well by up-expression of MMP-13 (42). In our study, drug therapy with doxazosin and BMP-7 showed greater recovery than spontaneous reversion, outstanding their promissory role in the treatment of fibrotic liver.

BMP-7 has inhibitory downstream activity over TGF- $\beta$ signaling, as Smad-1, -5 and -8 , avoiding the activation of
Smad-3/4 mediated by TGF- $\beta$ (24-26,43). Thus, when BMP-7 was administered, fibrosis deposition, some liver functions, HSCs hyperplasia, and expression changes in MMP and TIMP were favored to retrieve the functionality of the liver. Studies have also demonstrated how oral administration of a recombinant adeno-associated virus (AAV)-mediated BMP-7 transduction reduces the hepatic fibrosis and suppresses the activation of HSCs (44). Moreover, gene delivery of BMP-7 via polyethylenimine-conjugated gold nanoparticles in corneal tissue demonstrated diminution of $\alpha$-SMA positive cells and fibronectin, in model of corneal fibrosis after photorefractive keratectomy in rabbits (45). Besides, administration of recombinant human BMP-7 reduced tubular damage and tubulointerstitial fibrosis in streptozotocin-induced diabetic mice with renal disease (46). Recently, natural compounds have shown to promote the activation of BMP-7/Smad signaling, which in turn modified the serum, biochemical and histological markers of hepatic damage, indicating a diminution of liver fibrosis in a model of bile duct ligation-induced liver fibrosis (47).

Previous studies have reported a significant reduction in deposits of collagen type I in cirrhotic hamsters treated with Doxazosin, when it was administered during 6 weeks after liver damage development (13). The effect was related with a decrease in TGF- $\beta$ synthesis. We showed that when Doxazosin is only administered for 2 weeks, the beneficial effect on cirrhosis is maintained, as demonstrated by the decrease in the fibrotic area and collagen type I deposit in the liver of cirrhotic $\mathrm{CCl} 4$-induced hamsters. The antifibrotic effect of doxazosin has also been reported in renal fibrosis and myocardial interstitial fibrosis (48-50). As HSCs, the main fibrinogenic cells in liver, express $\alpha_{1}$-AR $(51,52)$ we argue that is the selective inhibition of this receptor in HSCs which is causing the decrease in number of activated cells and therefore in collagen synthesis. Some differences are reported between 2 or 6 weeks of treatment with Doxazosin in relation to liver enzymes. When it was administered thought 6 weeks ALT was significantly decreased (13), but no significant change in liver enzymes is observed after 2 weeks of treatment. However, the increase in plasma albumin after 2 weeks of treatment is indicative of liver function recovery.

As both experimental therapies are targeted to blockade (BMP-7) or inhibit (doxazosin) TGF- $\beta$ secretion, we hypothesized that co-administration of both therapies could have an improved effect on ECM deposition in the treated hamsters. In the present study, adenoviral-BMP-7 transduction as well as doxazosin therapy, demonstrated to reduce, significantly, the deposition of ECM, particularly of collagen type I, and to diminish the expression of $\alpha$-SMA in activated HSCs. We found that combination of both treatments do have neither synergic nor an additive effect on liver cirrhosis. Because of both treatments are targeted to blockade the same fibrogenic mechanisms $(13,31)$, probably the total capacity of inhibition has been achieved by individual therapies and then the combination is not able to improve the antifibrotic effect.

In addition, ALT levels were significantly reduced when combined therapies were administered, but AST and albumin productions were unchanged by comparison to BMP-7. It is not surprising that doxazosin treatment maintains increased levels of AST or ALT after two weeks of treatment, but apparent liver toxicity to the liver is reduced when BMP-7 is also administered. 
Previously, doxazosin was reported to cause liver toxicity at doses of $1 \mathrm{mg} / \mathrm{kg} /$ day at six weeks in the same model (13), moreover in the present study this toxicity is maintained at 2 weeks of treatment; outstanding BMP-7 gene therapy reduced toxic effect of doxazosin. These data are consistent with other study that have shown the protective effect of BMP-7 to hepatocytes, with improved liver function and regeneration (53).

Hepatocyte proliferation is also related to changes in the expression of regulatory genes involved in ECM remodeling $(53,54)$. In this regard, Arendt et al demonstrated that MMP-13 and TIMP-1 are differentially expressed after TGF- $\beta$ deprivation (55). Besides, previous studies had shown that the $\mathrm{N}-\mathrm{Myc}$ downstream-regulated gene 2 abrogates the profibrogenic TGF- $\beta$ activity by diminution of the expression of TIMP-2 mRNA (56). We demonstrated that down-expression of TIMP-2 mRNA correlate with reduction of collagen type I deposition in BMP-7 and doxazosin treated groups, however combinatory therapies were not as efficient as doxazosin alone.

In conclusion, the current study indicates that BMP-7 diminish the deposition of collagen type I by hampering the activation-proliferation of HSCs, and likely increasing hepatocyte proliferation. Although BMP-7 gene therapy did not improve the antifibrotic effect of doxazosin, it reduced its toxic effect in the liver. The combination of gene and drug therapies may not favor the increment of therapeutic effects, but its application can reduce adverse effects of conventional drugs.

\section{Acknowledgements}

The present study was supported by the grants (nos. 241312 and 134487) awarded by the National Council of Science and Technology (CONACYT), and PIBB15-10N from the Autonomous University of Aguascalientes. LRAM is a Postdoctoral Fellow awarded by CONACYT (grant no. 176507). Authors are grateful to Beatriz Orozco for excellent technical assistance and animal care.

\section{References}

1. Mokdad AA, Lopez AD, Shahraz S, Lozano R, Mokdad AH, Stanaway J, Murray CJ and Naghavi M: Liver cirrhosis mortality in 187 countries between 1980 and 2010: A systematic analysis. BMC Med 12: 145, 2014.

2. Muir AJ: Understanding the complexities of cirrhosis. Clin Ther 37: 1822-1836, 2015.

3. Ramos-Lopez O, Martinez-Lopez E, Roman S, Fierro NA and Panduro A: Genetic, metabolic and environmental factors involved in the development of liver cirrhosis in Mexico. World J Gastroenterol 21: 11552-11566, 2015.

4. Ibañez P, Solis N, Pizarro M, Aguayo G, Duarte I, Miquel JF, Accatino L and Arrese M: Effect of losartan on early liver fibrosis development in a rat model of nonalcoholic steatohepatitis. J Gastroenterol Hepatol 22: 846-851, 2007.

5. Friedman SL: Mechanisms of hepatic fibrogenesis. Gastroenterology 134: 1655-1669, 2008.

6. Garbuzenko DV, Arefyev NO and Belov DV: Mechanisms of adaptation of the hepatic vasculature to the deteriorating conditions of blood circulation in liver cirrhosis. World J Hepatol 8: 665-672, 2016.

7. Wang F, Liu S, Du T, Chen H, Li Z and Yan J: NF-кB inhibition alleviates carbon tetrachloride-induced liver fibrosis via suppression of activated hepatic stellate cells. Exp Ther Med 8: 95-99, 2014.

8. Shen M, Chen K, Lu J, Cheng P, Xu L, Dai W, Wang F, He L, Zhang Y, Chengfen W, et al: Protective effect of astaxanthin on liver fibrosis through modulation of TGF- $\beta 1$ expression and autophagy. Mediators Inflamm 2014: 954502, 2014.
9. Gu L, Deng WS, Sun XF, Zhou H and Xu Q: Rapamycin ameliorates $\mathrm{CCl} 4$-induced liver fibrosis in mice through reciprocal regulation of the Th17/Treg cell balance. Mol Med Rep 14: $1153-1161,2016$

10. Garcíade León MdelC,MontfortI,Tello MontesE,López Vancell R, Olivos García A, González Canto A, Nequiz-Avendaño M and Pérez-Tamayo R: Hepatocyte production of modulators of extracellular liver matrix in normal and cirrhotic rat liver. Exp Mol Pathol 80: 97-108, 2006.

11. Kang M, Zhao L, Ren M, Deng M and Li C: Zinc mediated hepatic stellate cell collagen synthesis reduction through TGF- $\beta$ signaling pathway inhibition. Int J Clin Exp Med 8: 20463-20471, 2015.

12. Hellerbrand C: Molecular targets for antifibrotic therapy in liver disease: Using magic bullets for crossfire rather than a one-sided shotgun attack. Gut 63: 1039-1041, 2014.

13. Muñoz-OrtegaMH,Llamas-RamírezRW,Romero-DelgadilloNI, Elías-Flores TG, Tavares-Rodríguez Ede J, Campos-Esparza Mdel R, Cervantes-García D, Muñoz-Fernández L, Gerardo-Rodríguez M and Ventura-Juárez J: Doxazosin treatment attenuates carbon tetrachloride-induced liver fibrosis in hamsters through a decrease in transforming growth factor $\beta$ secretion. Gut Liver 10: 101-108, 2016.

14. Ceral J and Solar M: Doxazosin: Safety and efficacy in the treatment of resistant arteria hypertension. Blood Press 18: 74-77, 2009.

15. Tahmatzopoulos A, Rowland RG and Kyprianou N: The role of alpha-blockers in the management of prostate cancer. Expert Opin Pharmacother 5: 1279-1285, 2004.

16. Mazzolini G, Alfaro C, Sangro B, Feijoó E, Ruiz J, Benito A, Tirapu I, Arina A, Sola J, Herraiz M, et al: Intratumoral injection of dendritic cells engineered to secrete interleukin-12 by recombinant adenovirus in patients with metastatic gastrointestinal carcinomas. J Clin Oncol 23: 999-1010, 2005.

17. Hahn GV, Cohen RB, Wozney JM, Levitz CL, Shore EM, Zasloff MA and Kaplan FS: A bone morphogenetic protein subfamily: Chromosomal localization of human genes for BMP5, BMP6, and BMP7. Genomics 14: 759-762, 1992.

18. Andrews PW, Damjanov I, Berends J, Kumpf S, Zappavigna V, Mavilio F and Sampath K: Inhibition of proliferation and induction of differentiation of pluripotent human embryonal carcinoma cells by osteogenic protein-1 (or bone morphogenetic protein-7). Lab Invest 71: 243-251, 1994.

19. Midorikawa Y, Ishikawa S, Iwanari H, Imamura T, Sakamoto H, Miyazono K, Kodama T, Makuuchi M and Aburatani H: Glypican-3, overexpressed in hepatocellular carcinoma, modulates FGF2 and BMP-7 signaling. Int J Cancer 103: 455-465, 2003.

20. Knight PG and Glister C: TGF-beta superfamily members and ovarian follicle development. Reproduction 132: 191-206, 2006.

21. Genander M, Cook PJ, Ramsköld D, Keyes BE, Mertz AF, Sandberg R and Fuchs E: BMP signaling and its pSMAD1/5 target genes differentially regulate hair follicle stem cell lineages. Cell Stem Cell 15: 619-633, 2014.

22. Su YH, Cai HB, Ye ZY and Tan WS: BMP-7 improved proliferation and hematopoietic reconstitution potential of ex vivo expanded cord blood-derived CD34(+) cells. Hum Cell 28: 14-21, 2015.

23. Beck SE, Jung BH, Fiorino A, Gomez J, Rosario ED, Cabrera BL, Huang SC, Chow JY and Carethers JM: Bone morphogenetic protein signaling and growth suppression in colon cancer. Am J Physiol Gastrointest Liver Physiol 291: G135-G145, 2016.

24. Pegorier S, Campbell GA, Kay AB and Lloyd CM: Bone morphogenetic protein (BMP)-4 and BMP-7 regulate differentially transforming growth factor (TGF)-beta1 in normal human lung fibroblasts (NHLF). Respir Res 11: 85, 2010.

25. Zhang P and Dressler GR: The Groucho protein Grg4 suppresses Smad7 to activate BMP signaling. Biochem Biophys Res Commun 440: 454-459, 2013.

26. Lim RR, Tan A, Liu YC, Barathi VA, Mohan RR, Mehta JS and Chaurasia SS: ITF2357 transactivates Id3 and regulate TGF/BMP7 signaling pathways to attenuate corneal fibrosis. Sci Rep 6: 20841, 2016.

27. Kaimori A, Potter J, Kaimori JY, Wang C, Mezey E and Koteish A: Transforming growth factor-betal induces an epithelial-to-mesenchymal transition state in mouse hepatocytes in vitro. J Biol Chem 282: 22089-22101, 2007.

28. Wang S and Hirschberg R: Bone morphogenetic protein-7 signals opposing transforming growth factor beta in mesangial cells. J Biol Chem 279: 23200-23206, 2004. 
29. Yanagita M: Inhibitors/antagonists of TGF- $\beta$ system in kidney fibrosis. Nephrol Dial Transplant 27: 3686-3691, 2012.

30. Yang G, Zhu Z, Wang Y, Gao A, Niu P and Tian L: Bone morphogenetic protein-7 inhibits silica-induced pulmonary fibrosis in rats. Toxicol Lett 220: 103-108, 2013.

31. Wang SL, Yang CQ, Qi XL, Yuan M, Chang YZ, Yang L and Gao HJ: Inhibitory effect of bone morphogenetic protein-7 on hepatic fibrosis in rats. Int J Clin Exp Pathol 6: 897-903, 2013.

32. Wang LP, Dong JZ, Xiong LJ, Shi KQ, Zou ZL, Zhang SN, Cao ST, Lin Z and Chen YP: BMP-7 attenuates liver fibrosis via regulation of epidermal growth factor receptor. Int J Clin Exp Pathol 7: 3537-3547, 2014.

33. Hernandez-Hurtado AA, Borrego-Soto G, Marino-Martinez IA, Lara-Arias J, Romero-Diaz VJ, Abrego-Guerra A, Vilchez-Cavazos JF,Elizondo-Riojas G,Martinez-RodriguezHG, Espinoza-Juarez MA, et al: Implant composed of demineralized bone and mesenchymal stem cells genetically modified with AdBMP2/AdBMP7 for the regeneration of bone fractures in ovis aries. Stem Cells Int 2016: 7403890, 2016.

34. Bradford MM: A rapid and sensitive method for the quantitation of microgram quantities of protein utilizing the principle of protein-dye binding. Anal Biochem 72: 248-254, 1976.

35. Schmittgen TD and Livak KJ: Analyzing real-time PCR data by the comparative C(T) method. Nat Protoc 3: 1101-1108, 2008

36. Kondou H, Mushiake S, Etani Y, Miyoshi Y, Michigami T and Ozono K: A blocking peptide for transforming growth factor-betal activation prevents hepatic fibrosis in vivo. J Hepatol 39: 742-748, 2003.

37. Osawa Y, Oboki K, Imamura J, Kojika E, Hayashi Y, Hishima T, Saibara T, Shibasaki F, Kohara M and Kimura K: Inhibition of cyclic adenosine monophosphate (cAMP)-response element-binding protein (CREB)-binding protein (CBP)/ $\beta$-catenin reduces liver fibrosis in mice. EBioMedicine 2: $1751-1758,2015$

38. Bravo E, D'Amore E, Ciaffoni F and Mammola CL: Evaluation of the spontaneous reversibility of carbon tetrachloride-induced liver cirrhosis in rabbits. Lab Anim 46: 122-128, 2012.

39. Maros T, Seres-Sturm L, Lakatos O, Seres-Sturm MT and Blazsek V: Spontaneous reversibility of advanced toxic liver cirrhosis. Acta Morphol Acad Sci Hung 23: 293-302, 1975.

40. Muriel P, Moreno MG, Hernández Mdel C, Chávez E and Alcantar LK: Resolution of liver fibrosis in chronic CCl4 administration in the rat after discontinuation of treatment: Effect of silymarin, silibinin, colchicine and trimethylcolchicinic acid. Basic Clin Pharmacol Toxicol 96: 375-380, 2005.

41. Chávez E, Segovia J, Shibayama M, Tsutsumi V, Vergara P, Castro-Sánchez L, Salazar EP, Moreno MG and Muriel P: Antifibrotic and fibrolytic properties of celecoxib in liver damage induced by carbon tetrachloride in the rat. Liver Int 30: 969-978, 2010.

42. Lv P, Meng Q, Liu J and Wang C: Thalidomide accelerates the degradation of extracellular matrix in rat hepatic cirrhosis via down-regulation of transforming growth factor- $\beta 1$. Yonsei Med J 56: 1572-1581, 2015 .
43. Xu F, Liu C, Zhou D and Zhang L: TGF- $\beta /$ SMAD pathway and its regulation in hepatic fibrosis. J Histochem Cytochem 64: 157-167, 2016.

44. Hao ZM, Cai M, Lv YF, Huang YH and Li HH: Oral administration of recombinant adeno-associated virus-mediated bone morphogenetic protein-7 suppresses $\mathrm{CCl}(4)$-induced hepatic fibrosis in mice. Mol Ther 20: 2043-2051, 2012.

45. Tandon A, Sharma A, Rodier JT, Klibanov AM, Rieger FG and Mohan RR: BMP7 gene transfer via gold nanoparticles into stroma inhibits corneal fibrosis in vivo. PLoS One 8: e66434, 2013.

46. Sugimoto H, Grahovac G, Zeisberg M and Kalluri R: Renal fibrosis and glomerulosclerosis in a new mouse model of diabetic nephropathy and its regression by bone morphogenic protein-7 and advanced glycation end product inhibitors. Diabetes 56 : $1825-1833,2007$.

47. Hou F, Liu R, Liu X, Cui L, Wen Y, Yan S and Yin C: Attenuation of liver fibrosis by herbal compound 861 via upregulation of BMP-7/Smad signaling in the bile duct ligation model rat. Mol Med Rep 13: 4335-4342, 2016.

48. Gallego-Delgado J, Lazaro A, Gomez-Garre D, Osende JI, Gonzalez-Rubio ML, Herraiz M, Manzarbeitia F, Fortes J, Fernandez-Cruz A and Egido J: Long-term organ protection by doxazosin and/or quinapril as antihypertensive therapy. J Nephrol 19: 588-598, 2006.

49. Perlini S, Palladini G, Ferrero I, Tozzi R, Fallarini S, Facoetti A, Nano R, Clari F, Busca G, Fogari R and Ferrari AU: Sympathectomy or doxazosin, but not propranolol, blunt myocardial interstitial fibrosis in pressure-overload hypertrophy. Hypertension 46: 1213-1218, 2005

50. Pawluczyk IZ, Patel SR and Harris KP: The role of the alpha-1 adrenoceptor in modulating human mesangial cell matrix production. Nephrol Dial Transplant 21: 2417-2424, 2006.

51. Oben JA, Roskams T, Yang S, Lin H, Sinelli N, Torbenson M, Smedh U, Moran TH, Li Z, Huang J, et al: Hepatic fibrogenesis requires sympathetic neurotransmitters. Gut 53: 438-445, 2004.

52. Oben JA, Roskams T, Yang S, Lin H, Sinelli N, Li Z, Torbenson M, Huang J, Guarino P, Kafrouni M and Diehl AM: Sympathetic nervous system inhibition increases hepatic progenitors and reduces liver injury. Hepatology 38: 664-673. 2003.

53. Sugimoto H, Yang C, LeBleu VS, Soubasakos MA, Giraldo M, Zeisberg M and Kalluri R: BMP-7 functions as a novel hormone to facilitate liver regeneration. FASEB J 21: 256-264, 2007.

54. Jirouskova M, Zbodakova O, Gregor M, Chalupsky K, Sarnova L, Hajduch M, Ehrmann J, Jirkovska M and Sedlacek R: Hepatoprotective effect of MMP-19 deficiency in a mouse model of chronic liver fibrosis. PLoS One 7: e46271, 2012.

55. Arendt E, Ueberham U, Bittner R, Gebhardt R and Ueberham E: Enhanced matrix degradation after withdrawal of TGF-beta1 triggers hepatocytes from apoptosis to proliferation and regeneration. Cell Prolif 38: 287-299, 2005.

56. Yang J, Zheng J, Wu L, Shi M, Zhang H, Wang X, Xia N, Wang D, Liu X, Yao L, et al: NDRG2 ameliorates hepatic fibrosis by inhibiting the TGF- $\beta 1 /$ Smad pathway and altering the MMP2/TIMP2 ratio in rats. PLoS One 6: e27710, 2011. 